\title{
RELATIVITY IN TRADE THEORY: TOWARDS A SOLUTION TO THE MYSTERY OF MisSING TRADE
}

\author{
ERIC O’N. FISHER \\ SHARON L. MAY
}

CESIFO WORKING PAPER NO. 1818

CATEGORY 10: EMPIRICAL AND THEORETICAL METHODS

OCTOBER 2006

Presented at CESifo Venice Summer Institute, Workshop ON

“Understanding the LAtest Wave of Regional Trade and CoOperation AgreEment, JULY 2006

\footnotetext{
An electronic version of the paper may be downloaded

- from the SSRN website:

- from the RePEc website:

- from the CESifo website:

www.SSRN.com

Www.RePEc.org

www.CESifo-group.de
} 


\title{
RELATIVITY IN TRADE THEORY: TOWARDS A SOLUTION TO THE MYSTERY OF MisSING TRADE
}

\begin{abstract}
Using OECD input output matrices consistently, we offer a tentative solution to the mystery of missing trade. First, we confirm the usual rejection of factor price equalization and identical technologies. Second, we develop a new technique to compute the factor content of trade when countries' technologies are different. Measuring factor content conventionally, we find a putative paucity of trade in these data. When factor content is measured correctly, theory predicts the direction and volume of trade more accurately. Thus measuring the factor content of trade according to the country of origin may vindicate the Heckscher-Ohlin-Vanek paradigm.
\end{abstract}

JEL Code: F1, D5, C67.

\author{
Eric O'N. Fisher \\ Orfalea College of Business \\ California Polytechnic State University \\ 1 Grand Avenue \\ San Luis Obispo, CA 93407 \\ USA \\ eric.on.fisher@gmail.com
}

\author{
Sharon L. May \\ Division of Social Sciences of Economics \\ Maryville College \\ 502 E. Lamar Alexander Parkway \\ Maryville, TN 37804 \\ USA \\ slmay@msn.com
}




\title{
Relativity in Trade Theory: Towards a Solution to the Mystery of Missing Trade
}

\author{
By ERIC O’N. FISHER AND SHARON L. MAY*
}

The Heckscher-Ohlin-Vanek paradigm, one of the most elegant constructs of applied economic theory, has predictions for both the direction and volume of trade. A country exports the goods that use its abundant factors intensively, and its trade volume reflects the difference between local and global factor endowments. Unfortunately, the theory has met with mixed empirical success at best. Edward E. Leamer (1984) noted that the model predicted the direction of trade poorly, and Daniel Trefler (1995) showed that measured trade in factors is two orders of magnitude too small. He calls this finding the mystery of missing trade. Many authors have investigated this phenomenon, and it seems to be a robust feature of the data. ${ }^{1}$ We argue that the primary reason for missing trade is that the literature has not measured the factor content of imports properly.

Robert C. Feenstra’s description (1998) of Rone Tempest’s (1996) Barbie doll is quite apt:

"The raw materials for the doll (plastic and hair) are obtained from Taiwan and Japan. Assembly ... has now migrated to low-cost locations in Indonesia, Malaysia, and China. The molds themselves come from the United States, as do additional paints used in decorating. ... Of the \$2 export value of the dolls when they leave Hong Kong for the United States, about 35 cents covers Chinese labor, 65 cents covers the cost of materials and the remainder covers transportation and overhead, including profits earned in Hong Kong. The doll sells for about \$10 in the United States, of which Mattel earns at least \$1, and the rest covers transportation, marketing, wholesaling, and retailing in the United States. The majority of value-added is therefore from U.S. activity. The dolls sell worldwide at the rate of two dolls every second, and this product alone accounted for $\$ 1.4$ billion in sales for Mattel in 1995.”

Here comes the million dollar question: What is Barbie’s factor content? 
The earliest studies of the factor content of trade boldly assumed that the input output matrix of the United States measured Barbie's factor content well enough, but subsequent work has recognized that countries’ production techniques may differ because of different factor prices or different technologies. Recent literature has been careful in its treatment of imported intermediate goods. ${ }^{2}$

Dalia S. Hakura (2001) sums up the implications of different local production techniques:

"Once international differences in production techniques are permitted, an ideal measure of factor content of trade would impute to traded goods those factors actually used in their production wherever that took place. This would require tracing the production history of all traded goods as well as the intermediate inputs used in their production. In addition, it would require obtaining data on factor input requirements for all countries that engage in international trade.”

She cautions, "Biased factor contents of trade in the strict HOV can lead to a discrepancy between the calculated factor content of trade and that predicted from endowments. ... This may provide an explanation for the 'mystery of the missing trade', first recognized by Trefler in the tests of the strict HOV model.” We explore one aspect of Hakura's insight -- the need to evaluate factor content according to local techniques -- and take it one step further by addressing the heterogeneity of factor services across countries.

Jaroslav Vanek's (1968) deep insight was that trade in goods is really trade in the factors used to produce them. Every study of the Heckscher-Ohlin-Vanek paradigm draws upon data describing the use of commodities and factors in the many sectors of an economy. Input output accounts describe commodity flows, but data on factor requirements and endowments usually come from other sources. Many studies have used 
industry-level surveys on machines, land, and workers per unit of output. Could it be that confounding sources of data have caused some of the mystery of missing trade? ${ }^{3}$

We are also concerned about measuring stocks and their corresponding flows accurately for some factors. Consider an acre of farmland in Ohio. Its price is around $\$ 2000$. If the real interest rate is 3 per cent and there is no depreciation, the user cost of an acre is $\$ 60$ per year. But how much of that price is actually attributed to the raw factor cropland? Every acre is a combination of raw land and all the capital improvements that have gone into it. Rents on land are really payments for the services of a bundle of land and capital, just as wages reflect human capital. This is true both when computing factor usage for an industry and the physical endowments of a country. An acre of cropland in Ohio is very different from an acre of cropland near Montepulciano in Tuscany, even though one can grow corn or wine grapes in either place. Measuring endowments in physical units is a tricky business at best. ${ }^{4}$

Concern with proper measurement of factors compels us to take a novel approach in this paper. We let the data speak for themselves. For us, the value of capital used in production is what actually appears in the input output account. Since we follow the input output accounts of nine OECD countries as closely as possible, we must pay a cost. The data allow us to identify only three factors of production: undifferentiated labor, private capital, and social capital. The input output tables report three measures of value added: compensation to employees, gross operating surplus, and indirect taxes. Thus those three categories are our notions of factors of production. ${ }^{5}$

We come full circle back to Barbie. Consider the deep implications of a trade theorist's way of thinking: Barbie herself is mobile, but factors of production that go into 
making her are not. So when factor prices differ, it is natural that countries might well produce the same Barbie in different ways. Hence, the shadow value of a unit of labor in France embodied in Barbie need not be the same as that for a Barbie made in Japan. An accurate empirical implementation of the model begs for a way to map French factor services into Japanese ones and vice versa. This is our main contribution.

How do we measure the factor content of trade? The factor content of exports is computed using the reporting country's input output matrix. Then we use data on bilateral trade to impute the factor content of imports by country of origin. But we still need to convert the services of factors in the country of origin into those in the importing country. That is why our factor conversion matrices are so important. In particular, we must ask, "What is one dollar of French labor (and no dollars of private capital and no dollars of social capital) worth in Japan?” The answer to this question involves a combination of Japanese labor services and private capital and social capital. The surprising empirical aspect of this mapping is that its three eigenvalues often have moduli less than unity; there is no aspect of the theory that says that this must be the case mathematically. So a Japanese econometrician might well think that French factors are not worth as much as the shadow value ascribed to them in France, and vice versa!

This phenomenon is why we call this paper a relativity theory of trade. Think of a person traveling without acceleration in a rocket ship going 90 per cent of the speed of light. Since the earth is an inertial frame of reference and the speed of light is constant for any observer, you would think her clock was ticking much slower than your own. But from her perspective, you too are traveling at 90 per cent of the speed of light, so she would think that your earth clock was measuring time more slowly than hers. Who is 
right? The special theory of relativity shows that you both are. Just as measuring time depends upon one's frame of reference, so does the value of factor services depend upon one's location.

The main difference between our approach and that of the literature is that we put Barbie back where she came from and then compute her local factor content in two steps: first, we calculate Barbie's factor content in her exporting country; and second, we translate foreign factor services into local ones. The first step is akin to measuring time in the rocket ship where Barbie was made, and the second step is analogous to correcting for time dilation in two different frames of reference. This two-step procedure brings us closer to a solution to the mystery of missing trade, and its data pass Leamer's (1984) sign test — the one based on the direction of trade—-well enough.

In sum, we come closer to reconciling the theory and the data for three reasons. First, we emphasize that factor services in one country are conceptually different from those in another, especially when factor prices are not equal. Second, we are careful to measure factors in values, not quantities. Third, we work with only three factors: labor, private capital, and social capital. The main reason that we are able to make progress towards solving the mystery of missing trade is that we are careful in analyzing imports of factor services in a world without factor price equalization.

\section{Input Output Accounting in Quantities and in Values}

Consider the following partitioned matrix:

$$
\underset{(\ell+f) \times(\ell+q)}{\left[\begin{array}{cc}
\mathbf{A} & \mathbf{Z} \\
\mathbf{B} & \mathbf{0}
\end{array}\right]}
$$


where $\underset{\ell \times \ell}{\mathbf{A}}$ is the matrix of input requirements for the $\ell$ sectors, $\underset{f \times \ell}{\mathbf{B}}$ is the matrix of direct factor requirements for the $f$ factors, $\underset{\ell \times q}{\mathbf{Z}}$ is a matrix of exogenous demands for goods for $q$ different uses, and $\underset{f \times q}{\mathbf{0}}$ is a conformable matrix of zeros. ${ }^{6}$ Each row totals gives the gross output or total supply of the corresponding good or factor. Likewise, each of the first $\ell$ column totals shows the input usage of any good, and each of the last $q$ columns gives the total demand for an exogenously specified category.

There are only two consistent ways to do input-output accounting: the quantity approach or the value approach. Wassily Leontief himself (1986, p. 23) recommended using quantities, and in this case $a_{i j}$ is how many units of good $i$ are used in the producing the output of good $j$. The direct factor requirement of that sector $b_{i j}$ tells how many units of factor $i$ are used in producing the output of good $j$. The value approach-the one used in the OECD STAN database--is such that all of the elements of this matrix are denominated in units of local currency, not in physical quantities. In this case, the normalized input output matrix gives the cost shares of intermediate inputs and primary factors for each activity.

Let $\mathbf{B}^{c}\left(\mathbf{I}-\mathbf{A}^{c}\right)^{-1}$ be the matrix describing the direct and indirect factor requirements in country $c$ in quantity terms. The analog in the value approach is:

$$
\underset{f \times \ell}{\Theta^{c}}=\underset{f \times f}{\mathbf{W}_{f \times \ell}^{c}} \mathbf{B}^{c}\left(\mathbf{I}-\mathbf{A}_{\ell \times \ell}^{c}\right)^{-1} \underset{\ell \times \ell}{\mathbf{P}^{-1}},
$$

where $\mathbf{W}^{c}$ is the diagonal matrix whose typical element gives the factor price for factor $j \in\{1, \ldots, f\}$ and $\mathbf{P}$ is the diagonal matrix whose typical element is the world price of commodity $i \in\{1, \ldots, \ell\}$. Production techniques $\mathbf{B}^{c}\left(\mathbf{I}-\mathbf{A}^{c}\right)^{-1}$ and factor prices $\mathbf{W}^{c}$ may 
differ between countries, but we assume that every country faces the same international prices $\mathbf{P}$. Since $\mathbf{B}^{c}\left(\mathbf{I}-\mathbf{A}^{c}\right)^{-1}=\left(\mathbf{W}^{c}\right)^{-1} \boldsymbol{\Theta}^{c} \mathbf{P}$, one can go back and forth easily between the two approaches if one knows local factor prices and global goods prices.

All of input-output analysis is based upon the assumption of a fixed coefficient (Leontief!) technology. This is precisely the case where factor prices have no effect on the technology matrices $\mathbf{A}^{c}$ and $\mathbf{B}^{c}$. In practice these matrices are different among the advanced industrial economies because factor prices are not equalized or perhaps local technologies are not identical. If the researcher is going to let the consistent data from national accounts speak for themselves, then he or she is almost impelled to use the value approach in empirical implementations of the Heckscher-Ohlin-Vanek paradigm.

\section{Conceptual Foundations for Tests of the Theory}

Let $\mathcal{C}$ be an index set of countries; we denote the net output vector of country $c \in \mathcal{C}$ by $\mathbf{y}^{c}$ and its endowment by $\mathbf{v}^{c}$. Fix local factor prices and world goods prices. Then the full employment condition in value terms

$$
\mathbf{W}^{c} \mathbf{v}^{c}=\boldsymbol{\Theta}^{c} \mathbf{P} \mathbf{y}^{c}
$$

is a system of $f$ equations in the $\ell$ unknown elements of $\mathbf{P y}^{c}$. This system has a set of solutions of dimension $\ell-f$, but every solution has the same factor content $\mathbf{W}^{c} \mathbf{v}^{c}$. Equation (1) shows that the value approach is a theory of factor use when prices are fixed. If local factors are in fixed supply, then the value approach can be interpreted as a theory of local factor payments for a given vector of world goods prices.

Let $\left(\Theta^{c}\right)^{+}$be the Moore-Penrose inverse of the direct and indirect factor content matrix. ${ }^{7}$ The natural projection of the values of factors services onto those of outputs is: 


$$
\mathbf{P} \mathbf{y}^{c}=\left(\boldsymbol{\Theta}^{c}\right)^{+} \mathbf{W}^{c} \mathbf{v}^{c}=\left[\mathbf{B}^{c}\left(\mathbf{I}-\mathbf{A}^{c}\right)^{-1} \mathbf{P}^{-1}\right]^{+} \mathbf{v}^{c}
$$

This projection depends upon factor prices only if the local technology does. ${ }^{8}$ The term in square brackets is the direct and indirect physical factor requirements per dollar's worth of output. It is the multi-dimensional analog of the Lerner diagram, and the term $\mathbf{P}^{-1}$ is a reminder that we are implicitly defining unit-value isoquants.

What is the economic intuition behind the Moore-Penrose inverse? For fixed prices, $\left(\Theta^{c}\right)^{+}$is a linear mapping from the space of the endowments into the space of outputs. Its typical element gives the marginal effect of an increase in the endowment of factor $j$ on the value of output of good $i$. Hence $\left(\Theta^{c}\right)^{+}$is a Rybczynski matrix!

Let $\hat{\mathbf{P}}$ be the diagonal matrix whose canonical element is $d p_{i} / p_{i}$ and let $\hat{\mathbf{W}}^{c}$ be analogous. Then changes of output prices and those of factor prices are related by:

$$
\hat{\mathbf{P}} \underset{\ell \times 1}{\mathbf{i}}=\left(\boldsymbol{\Theta}^{c}\right)^{T} \hat{\mathbf{W}}^{c} \underset{f \times 1}{\mathbf{i}}
$$

where $\underset{\ell \times 1}{\mathbf{i}}$ and $\underset{f \times 1}{\mathbf{i}}$ are just vectors of ones. Equation (2) states that changes in output prices are industry-specific weighted averages of changes in local factor costs if every sector is active. If the local industry-specific factor shares are known, then (2) is an overdetermined system of $\ell$ equations in the $f$ unknown diagonal elements of $\hat{\mathbf{W}}^{c}$. A trade theorist is quick to point out that only for the "right" configuration of world prices $\mathbf{P}$ can all $\ell>f$ sectors in the local economy operate with strictly positive output. If the matrix describing local industry-specific factor shares has full column rank, $\hat{\mathbf{W}}^{c} \underset{f \times 1}{\mathbf{i}}=\left[\left(\Theta^{c}\right)^{+}\right]^{T} \hat{\mathbf{P}} \underset{\ell \times 1}{\mathbf{i}}$ is the unique solution to this system of equations, and the transpose 
of the Rybczynski matrix is a Stolper-Samuelson matrix, as it should be. (Here we have used the fact that $\left[\left(\Theta^{c}\right)^{T}\right]^{+}=\left[\left(\Theta^{c}\right)^{+}\right]^{T}$.)

But what is so special about the Moore-Penrose inverse itself? The system (2) is over determined, and a trade theorist's strict interpretation of the full employment conditions (1) implies that any marginal change in prices would cause the outputs of all goods to change drastically. Only the most profitable sectors would survive if the price of one good rose even by one penny! Of course the empirical trade economist cannot be so picky. She would recognize that almost every sector in each country continues to operate with strictly positive outputs when prices change marginally, and she would remind her theoretically oriented brother that a model with only a few mobile factors is an approximation of the real world.

What would the theoretical brother and empirical sister agree on as a "best linear approximation” of the effect of changes in goods price on the returns to local factors? For an over-determined system, the Moore-Penrose inverse is the least squares estimator. Hence, the factor price changes that best fit the system (2) are just the least squares estimator of a regression of changes in world prices onto local factor shares:

$$
\hat{\mathbf{W}}^{c} \underset{f \times 1}{\mathbf{i}}=\left[\Theta^{c}\left(\Theta^{c}\right)^{T}\right]^{-1} \boldsymbol{\Theta}^{c} \hat{\mathbf{P}} \underset{\ell \times 1}{\mathbf{i}}=\left[\left(\Theta^{c}\right)^{T}\right]^{+} \hat{\mathbf{P}} \underset{\ell \times 1}{\mathbf{i}}=\left[\left(\boldsymbol{\Theta}^{c}\right)^{+}\right]^{T} \hat{\mathbf{P}} \underset{\ell \times 1}{\mathbf{i}} .
$$

Thus the Rybczynski matrix $\left(\Theta^{c}\right)^{+}$is intimately related to the econometrician's best estimate of the Stolper-Samuelson effects when every sector stays active for small changes in prices.

\section{A. The Measured Factor Content of Trade}

Let $\mathbf{h}^{c}$ be the final demand for commodities in country $c$. The conventional Leontief (value) measure of the factor content of trade for that country is: 


$$
\mathbf{W}^{c} \mathbf{r}^{c}=\Theta^{c} \mathbf{P} \mathbf{z}^{c}
$$

where $\mathbf{W}^{c} \mathbf{r}^{c}$ is the value at local factor prices of the resource content of trade and $\mathbf{P z} \mathbf{z}^{c}=\mathbf{P}\left(\mathbf{y}^{c}-\mathbf{h}^{c}\right)$ is the vector of net exports in value terms.

If each $\boldsymbol{\Theta}^{c}$ has full column rank, the local country-c value of a vector of resources located in $c^{\prime}$ is uniquely determined by the $f \times f$ matrix

$$
\mathbf{F}\left(c, c^{\prime}\right) \equiv \boldsymbol{\Theta}^{c}\left(\Theta^{c^{\prime}}\right)^{+}
$$

For example, the value in country $c$ of the entire endowment vector of country $c$ ' is

$$
\mathbf{F}\left(c, c^{\prime}\right) \mathbf{W}^{c^{\prime}} \mathbf{v}^{c^{\prime}}=\boldsymbol{\Theta}^{c}\left(\Theta^{c^{\prime}}\right)^{+} \mathbf{W}^{c^{\prime}} \mathbf{v}^{c^{\prime}}=\mathbf{W}^{c}\left[\mathbf{B}^{c}\left(\mathbf{I}-\mathbf{A}^{c}\right)^{-1} \mathbf{P}^{-1}\right]\left[\mathbf{B}^{c^{\prime}}\left(\mathbf{I}-\mathbf{A}^{c^{\prime}}\right)^{-1} \mathbf{P}^{-1}\right]^{+} \mathbf{v}^{c^{\prime}}
$$

The interpretation of this expression is instructive. The rightmost term is the list of endowments in the country of origin. The second term from the right is the physical Rybczynski matrix for that country. The third term from the right captures the direct and indirect factor requirements per dollar's worth of output in the importing country. The fourth term from the right is the importing country's factor prices $\mathbf{W}^{c}$. The product $\left[\mathbf{B}^{c}\left(\mathbf{I}-\mathbf{A}^{c}\right)^{-1} \mathbf{P}^{-1}\right]\left[\mathbf{B}^{c^{\prime}}\left(\mathbf{I}-\mathbf{A}^{c^{\prime}}\right)^{-1} \mathbf{P}^{-1}\right]^{+}$differs from the identity matrix only if the two countries have different Rybczynski matrices. This difference can occur for only two possible reasons: (1) the two countries have disparate direct factor requirements; or (2) they use intermediate goods in different ways.

Thus our factor conversion matrices - which are observable in the datatransform endowments in the country of origin into those in the destination country in a natural way for a trade theorist. Each converter matrix follows these steps: (1) calculate Rybczynski effects in the country of origin; (2) calculate the local factor content of the requisite basket of goods in the country of destination; and (3) evaluate this content 
according to local factor prices. Thus equation (3) translates the shadow values of resources in country $c^{\prime}$ if they had to be used in $c$. These shadow values presumably capture differences in factor prices, productivity levels, uses of intermediate inputs, and generalized notions of trade costs. The fundamental paradigm in trade generally assumes that these shadow values differ across countries.

We can now define a more precise notion of the factor content of trade. Let the observable net trade vector for country $c$ be $\mathbf{P} \mathbf{z}^{c}=\mathbf{P}\left[\mathbf{x}^{c}-\sum_{c^{\prime} \neq c} \mathbf{m}\left(c, c^{\prime}\right)\right]$ where $\mathbf{x}^{c}$ is that country's vector of exports and $\mathbf{m}\left(c, c^{\prime}\right)$ is the vector of imports into $c$ from trading partner $c^{\prime}$. Then the Fisher-May measure of the factor content of trade for country c is

$$
\mathbf{W}^{c} \boldsymbol{\rho}^{c} \equiv \boldsymbol{\Theta}^{c} \mathbf{P} \mathbf{x}^{c}-\sum_{c^{\prime} \neq c} \mathbf{F}\left(c, c^{\prime}\right) \boldsymbol{\Theta}^{c^{\prime}} \mathbf{P} \mathbf{m}\left(c, c^{\prime}\right)
$$

where $\rho^{c}$ is the domestic resource content of the local net trade vector. Several comments are in order. First, one needs data on exports and bilateral imports. Fortunately, most of the requisite data are in the OECD STAN database. Second, (4) keeps track of trade flows between two reporting countries. If goods are imported and reexported several times, then an analog of (4) repeatedly applying linear mappings like $\mathbf{F}\left(c, c^{\prime}\right) \mathbf{F}\left(c^{\prime}, c^{\prime \prime}\right)$ is apposite. ${ }^{9}$ Third, the factor content of exports $\mathbf{P} \Theta^{c} \mathbf{x}^{c}$ is based upon the assumption that exports are made locally. Fourth, it is not generally true that $\mathbf{F}\left(c^{\prime}, c\right) \mathbf{F}\left(c, c^{\prime}\right)=\mathbf{I}$. This two-step mapping asks, for example, what happens to factors in France if they were exported to Japan and then re-imported into France; the empirical analysis shows that much is lost in translation.

\section{B. The Predicted Factor Content of Trade}


Now that we have defined the measured factor content of trade, we can proceed to the task of characterizing the predicted factor content of trade. Of course predicting the factor content of trade depends upon a particular model of demand and supply. Let $s^{c}=\mathbf{P} \mathbf{y}^{c} \underset{\ell \times 1}{\mathbf{i} /} \underset{c \in \mathcal{C}}{\mathbf{P} \mathbf{y}^{c}}{ }_{\ell \times 1}^{\mathbf{i}}=\mathbf{W}^{c} \mathbf{v}^{c} \underset{f \times 1}{\mathbf{i}} / \sum_{c \in \mathcal{C}} \mathbf{W}^{c} \mathbf{v}^{c} \underset{f \times 1}{\mathbf{i}}$ be the share of country $c$ in the aggregate demand for traded goods among the countries in $\mathcal{C}$. Since the factor content of trade is just the difference between factors supplied and the embodied factor content of goods demanded, the predicted factor content of trade is:

$$
\mathbf{W}^{c}\left[\mathbf{v}^{c}-s^{c} \overline{\mathbf{v}}^{c}\right]
$$

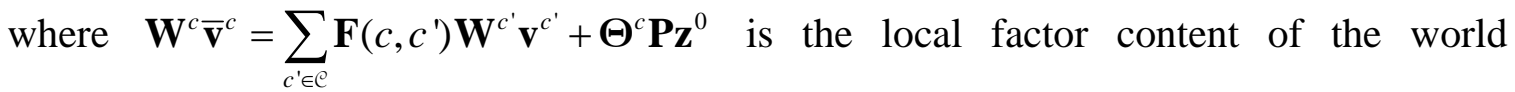
endowment and $\mathbf{z}^{0}$ is net exports from the rest of the world. ${ }^{10}$ In essence, equation (5) says that Vanek's factor content of trade is a country's supply of factors net of its demand for them, evaluated using the local technology. The first term $\mathbf{W}^{c} \mathbf{v}^{c}=\boldsymbol{\Theta}^{c} \mathbf{P} \mathbf{y}^{c}$ is just a restatement of the local full employment condition, and the second term $s^{c} \mathbf{W}^{c} \overline{\mathbf{v}}^{c}$ is the country's share of the local factor content of the world endowment. Of course, we have assumed that each country demands the same basket of traded goods and that the volume of imports is determined by income share.

If all countries' technologies are identical and there is factor price equalization, then $\boldsymbol{\Theta}^{c}=\boldsymbol{\Theta}$ and $\mathbf{W}^{c}=\mathbf{W}$ for every $c$. Then (5) reduces to the more familiar:

$$
\mathbf{W}\left[\mathbf{v}^{c}-s^{c} \overline{\mathbf{v}}\right]
$$

$\mathbf{W} \overline{\mathbf{v}}=\mathbf{W} \sum_{c^{\prime} \in \mathcal{C}} \mathbf{v}^{\mathbf{c}^{\prime}}+\Theta \mathbf{P} \mathbf{z}^{0}$ is the factor content of world endowments, including net trade with the rest of the world. The usual tests of the theory compare $\mathbf{W}^{c} \mathbf{r}^{c}$ with (6), and one 
has traditionally done the comparisons in quantities of factors. It is worth emphasizing that (5) is more general than (6), and (5) forms the basis for calculating our predicted factor content of trade. The formula (5) is one of our contributions because it shows exactly how to calculate the local factor content of any combination of world output that satisfies the full employment conditions. It makes no assumptions about factor price equalization or identical technologies, and it uses each country's resource constraints naturally. It is also easy to implement using the data!

What about the fact that some goods may not be traded? Assume that there are $\ell_{1}$ traded goods and $\ell_{2}$ not traded goods, where $\ell_{1}+\ell_{2}=\ell$. Then partition the direct and indirect factor requirements matrix as:

$$
\Theta^{c}=\left[\begin{array}{ll}
\Theta_{1}^{c} & \Theta_{2}^{c}
\end{array}\right]
$$

where the $\ell_{1}$ columns in $\Theta_{1}^{c}$ correspond to traded goods and $\ell_{2}$ columns in $\Theta_{2}^{c}$ to not traded goods. Then we may calculate the endowments left for trade as:

$$
\mathbf{W}^{c} \mathbf{v}_{1}^{c}=\mathbf{W}^{c}\left[\mathbf{v}^{c}-\left[\begin{array}{ll}
\mathbf{0} & \Theta_{2}^{c}
\end{array}\right] \mathbf{P y}^{c}\right]
$$

where the subscripts refer to traded and not traded goods in a natural way. The second term in this expression is the factor content of not traded goods. Hence the predicted factor content of trade now is:

$$
\mathbf{W}^{c}\left[\mathbf{v}_{1}^{c}-s^{c} \overline{\mathbf{v}}_{1}^{c}\right]
$$

where now $\overline{\mathbf{v}}_{1}^{c}=\sum_{c^{\prime} \in \mathcal{E}} \mathbf{F}^{c}\left(c, c^{\prime}\right) \mathbf{W}^{c^{\prime}} \mathbf{v}_{1}^{c^{\prime}}+\Theta^{c} \mathbf{P} \mathbf{z}_{1}^{0}$ with $\Theta^{c} \mathbf{P} \mathbf{z}_{1}^{0}$ being net exports of traded goods from the rest of the world $s^{c}$ is again the country's income share in the group. Note that income from not-traded goods normally enters into the demand for traded goods, especially in a system with homothetic preferences. 
The first part of our empirical analysis consists of tacking up red herrings. We do this to replicate the existing literature using our consistent value-based approach to inputoutput accounting. Our major empirical contribution comes in the second part where we use bilateral trade flows to calculate the Fisher-May measure of the factor content of trade in (4) to show that the predictions from the model described by (7) fit the data well by the standards of this literature. We don't have perfect predictive accuracy, but we show that an important culprit in the mystery of missing trade is a failure to account for differences in the proper valuation of factor services across countries.

\section{Empirical Results}

Web links to the data and their sources are given in the Data Appendix. We take this opportunity to reiterate that we have made every possible effort to use consistent measurements of factor services and input requirements.

As Davis and Weinstein (2001) have already noted, the assumption of identical technologies and factor price equalization is rejected immediately in these data. The matrices of factor shares are far from identical among the nine countries in our sample. This leaves the question: How different are the technologies among this set of advanced industrial countries? A natural measure of how similar two countries are is the correlation across the 36 industries in our sample of any factor's shares. Table 1 shows the sample correlations by country pair for each of the three factors.

--Insert Table 1 here.--

It is perhaps encouraging that most of these correlations are positive, but it is quite obvious, for example, that labor's cost shares in Canadian and Japanese industries are quite different. There may be differences in the qualities of workers, in wage rates, or 
in the economies' uses of intermediate inputs that affect the indirect use of labor. It is also interesting that the structure of social capital in the United Kingdom is quite different from that of the other countries. ${ }^{11}$ One can only make sense of the measured factor content of trade by evaluating production according to the local technology and then translating appropriately across countries.

It is also immediately obvious that Hicks-neutral technical differences cannot account for the different supply sides of these countries. If this explanation were the only reason for technological differences, then all these correlations would be unity. Also, it is not possible to model the difference between countries' technologies using only different efficiency parameters for factors as done by Trefler (1993b). The data show that factor productivities differ by industry. The actual input-output matrices give a much richer description of the interplay between technology and factor prices than can be captured by modifications of a model with country-specific and factor-specific technological differences. We confirm Xavier Gabaix's (1997) rejection of what he calls the Heckscher-Ohlin-Vanek-Leontief hypothesis. We also verify Peter K. Schott’s (2003) observation that the same industries use very different mixes of factors, even in this fairly homogeneous sample of advanced industrial countries.

Figure 1 shows the value-weighted aggregate factor shares for these economies; since these shares are largely consistent with macroeconomic data, ${ }^{12}$ it serves as an important check on the internal consistency of these matrices of direct and indirect factor requirements. One of our small contributions is to measure the share of social capital in national output, and these shares seem reasonable from a macroeconomic perspective.

--Insert Fig. 1 here.-- 


\section{A. Rounding Up the Usual Suspects}

The first step is to check the consistency of the input output tables and our measures of factor services. This analysis is what Davis and Weinstein (2001) call the production test. Figure 2 plots the endowments $\mathbf{W}^{c} \mathbf{v}^{c}$--measured in flows of 1985 dollars and derived independently from the income side of the OECD national accounts-against the factor content of domestic output $\boldsymbol{\Theta}^{c} \mathbf{P y}{ }^{c}$. In theory, the correlation should be perfect, but there are some small discrepancies having to do with the difference between the income and product sides.

--Insert Fig. 2 here.--

The second step compares the conventional factor content of trade with its predicted value using the simplest demand-side assumptions. Figure 3 plots the conventional Leontief measure of the factor content of trade $\mathbf{W}^{c} \mathbf{r}^{c}=\Theta^{c} \mathbf{P} \mathbf{z}^{c}$ against $\mathbf{W}^{c}\left[\mathbf{v}^{c}-s^{c} \overline{\mathbf{v}}^{c}\right]$ in equation (5). We used national expenditure measures from our data to determine the consumption shares $s^{c}$, and we took the net exports from the rest of the world $\mathbf{P z}^{0}$ as given; this vector too is in our data, since the material balances condition implies that $\mathbf{P} \mathbf{z}^{0}=-\mathbf{P} \sum_{c \in \mathcal{E}}\left(\mathbf{y}^{c}-\mathbf{h}^{c}\right) \cdot{ }^{13}$ Figure 3 is the same old sad story; the theory misses by two orders of magnitude. We have 27 observations on the ratio of the conventionally measured factor content of trade to its predicted value. The median of these measures is only 3 per cent! Also, we get only 11 of 27 signs right, worse than a coin flip. This step replicates the literature and serves as our base case.

--Insert Fig. 3 here.-- 
The third step is to examine the effect of not traded goods. Davis and Weinstein (2001) assume that only goods 1 through 24 are traded. Unfortunately, there is a large amount of international trade in these data in almost all of the sectors that those authors called not traded. ${ }^{14}$ What is the right definition of a not traded good?

We used two approaches in the empirical implementation. In the first one, we just did what Davis and Weinstein (2001) had done. In the second approach, we called a good not traded if the volume of trade between the OECD and the rest of the world was less than 2 per cent of gross OECD output. ${ }^{15}$ It does not make much difference whether we used the Davis and Weinstein definition or our own; the model does almost as badly as before. We plot the data for our narrower definition of not traded goods in Figure 4 . It shows the conventional Leontief measure of the factor content of trade $\mathbf{W}^{c} \mathbf{r}^{c}$ (the same data as before because we wanted to make consistent comparisons across models) against predicted factor content of trade $\mathbf{W}^{c}\left[\mathbf{v}_{1}^{c}-s^{c} \boldsymbol{\Theta}_{1}^{c} \mathbf{P} \mathbf{y}_{1}^{c}\right]$, where the latter measure lets factors be used up in the production of not traded goods. The good news is that the sign test has 15 out of 27 correct predictions for either approach; it predicts the direction of flows of labor now fairly well. But the bad news is that the volume of trade is still wrong by two orders of magnitude. For either definition of not traded goods, the median value of the ratio of measured to predicted trade flows is not bigger than 4 per cent now!

--Insert Fig. 4 here.--

Although this is a bit discouraging, it is to be expected. Still, we have derived a very important insight. There are two possible sources of error: (1) the demand specification is wrong; or (2) the measure of the factor content of trade is incorrect. Fisher and May (2005) explore the demand side and conclude that the former possibility 
does not solve the mystery of missing trade. ${ }^{16}$ The latter alternative subsumes the notion that there is no simple way to amalgamate factors of production across countries. Since the production test showed that we are measuring the factor content of local production correctly, there is strong evidence that the difficulty lies in measuring the factor content of imports. ${ }^{17}$ Proposing a solution to this problem is the heart of our empirical work.

\section{B. A Tentative Solution to the Mystery}

The Moore-Penrose inverse of the factor shares matrix helps translate foreign factor services into their domestic equivalents. The Fisher-May measure of the factor content of trade in (4) makes this conversion. Exports $\mathbf{P x}^{c}$ are produced locally, and their local factor content is simply $\Theta^{c} \mathbf{P} \mathbf{x}^{c}$. However, the local factor content of imports depends upon where they were made; this is why the factor conversion matrices $\mathbf{F}\left(c, c^{\prime}\right)=\Theta^{c}\left(\Theta^{c^{\prime}}\right)^{+}$are so important. These matrices take factors in the exporting country c' and convert them into local factors in the importing country $c$.

The complete list of $72=8 \times 9$ non-trivial converter matrices is empirically observable. Each matrix has three eigenvectors, and the moduli of the corresponding eigenvalues tell us whether international trade "shrinks" or "stretches" factors of production. There is no reason a priori to favor one side over the other. Indeed, if every country shared an identical technology and factor prices were equalized, then $\Theta^{c}=\Theta^{c^{\prime}}$ and every $\mathbf{F}\left(c, c^{\prime}\right)=\mathbf{I}$, with all 216 eigenvalues having modulus unity. The complete distribution of the moduli of the eigenvalues in our data is given in Figure 5. A vast number of these moduli are well less than unity; their average is 0.6. This means that every time a good is shipped from one major OECD country to another, its correctly measured local factor content will shrink on average by 40 per cent! 


\section{--Insert Figure 5 here.--}

There are three reasons that these factor conversion matrices may shrink the local factor content of goods made abroad. First, factor price differences may not completely reflect productivity differences. Second, countries may use different mixes of intermediate inputs in ways that are not entirely offset by factor prices. Third, the most likely reason that the conventional measures of the factor content of trade are biased towards zero is that the degree of variability of factor proportions within a sector and across countries is often at least as great as the variance across sectors within a country. The Technical Appendix develops three illustrative examples along these lines.

At the typical level of aggregation in this kind of empirical work, every sector has significant two-way trade. Hence net exports will measure little factor content if one does not adjust for factor use in the country of origin. Our factor conversion matrices are the most natural way to do so while still respecting the level of aggregation that is inherent in these data. The factor use coefficients in any country's input output accounts are designed to measure the factor content of domestic production well, but they cannot measure the factor content of goods produced abroad accurately.

Trefler (1993b) showed that one can fit the measured factor content of trade exactly by allowing for factor-specific and country-specific productivity differences. He demonstrated, for example, that workers in Bangladesh are 2 per cent as productive as those in the United States. Trefler's factor conversion matrices are simply a diagonal version of our more general linear mapping. Hence our empirical analysis indicates that his specification may be too simple. Indeed, a unit of labor in the United States is more appropriately considered an amalgam of all the factors in Bangladesh, not just labor in 
Dacca. If countries use intermediate inputs in different ways but have identical direct factor contents of production, their direct and indirect uses of labor may differ because each country's Leontief matrix may well be adapted to local conditions such as taxes and domestic complementarities between factors and intermediate inputs.

There is an important limitation in implementing the Fisher-May measure of the factor content of trade in these data. We have exports from each of the nine countries, and we have bilateral imports from each of them. We can also calculate imports from the rest of the world as a residual. But we do not have the direct and indirect factor requirements matrix for the rest of the world. Thus we cannot construct converter matrices for imports from the rest of the world into each of the reporting countries. This conversion was not a problem when using the Leontief measure of the factor content of imports because it was calculated using only the importing country's technology. The Fisher-May measure of the factor content of trade forces us to take a stand on technology in the rest of the world.

Since we do not have any information about $\Theta^{0}$, the direct and indirect factor requirements for the rest of the world, we use an old macroeconomist's trick and simulate these matrices. We used 65,000 random draws of column stochastic $\Theta^{0}$ matrices of dimension $3 \times 36$; again this is being conservative because occasionally in the OECD data there is a column of zeros in $\Theta^{c}$. Each such matrix can be used to construct the converter matrix $\mathbf{F}(c, 0)$ for imports into an OECD reporting country $c$ from the rest of the world, denoted by the index 0 . Building on this technique, we can easily construct the ratios of the Fisher-May measured factor content of trade to the predicted factor content of trade for the 27 factors in each simulation. 
A minor limitation in implementing the Fisher-May measure is that the OECD reports bilateral trade only for a subset of industries in the input output matrices. In particular, it does not report trade in the two sectors agriculture, forestry \& fishery and mining and quarrying and in twelve other sectors, numbered 25 through 36 in the Data Appendix, that are traditionally considered not traded goods. Hence, we use the predicted factor content of trade in Equation (7), following Davis and Weinstein's (2001) definition of not traded goods. We are being slightly conservative here because the theory would predict some factor content of trade in the first two sectors.

Table 2 reports the salient statistics. The model summary statistic is the median across the 27 factors of the ratios of the Fisher-May measured factor content of trade to the predicted factor content of trade. The reader will recall that this statistic was negative for the base-case trade model, and until now it has never been higher than 0.04 in all the twists and turns that have used the Leontief measure of the factor content of trade. The first row gives the best simulation result, the second row gives the worst simulation result, the third row gives the median across all simulations, and the fourth row gives the analogous mean. The numbers in parentheses are the sample standard deviations.

It is best to focus on the row labeled Mean. Across the 65,000 draws of random factor content matrices for the rest of the world, the model with not traded goods explains 22 per cent or more of the volume of trade for at least half of the 27 factors. This may not seem like much, but it is worth emphasizing that we are making none of the usual corrections for heteroscedasticity across countries and factors.

--Insert Table 2 here.-- 
The model also does well enough on the sign test. The average number of correct signs is roughly 17; the p-value of this statistic under the null hypothesis that the model is just a coin flip is 0.94 . Thus we can reject the null for a test of size 10 per cent, but not for a test of size 5 per cent. Still, using the Fisher-May measure of the factor content of trade allows the simplest model to beat any other parsimonious model on the sign test by a mile. The worst possible outcome is better than anything the reader has seen so far in this paper or in any other parsimonious specification in the literature.

Our best result is shown in Figure 6. This figure gives the models predictions for the best fit — the highest median value of the ratio of the Fisher-May measured factor content of trade to the predicted factor content of trade-among the 65,000 draws in the simulation. This draw does well because it fits the Fisher-May measured imports of capital and labor services into the United States well. The biggest outlier is for labor services in Japan, the point in the upper left quadrant; the Fisher-May measure shows that Japan is exporting labor, but the simplest model predicts that it should import it. Japanese exports of capital are another outlier; the Fisher-May measure has Japan exporting a lot of capital services, but the simple model prediction is for much smaller exports of these services.

--Insert Figure 6 here.--

\section{Conclusion}

We have shed light on the mystery of missing trade. The main point of our paper is that this putative mystery has largely to do with measuring the factor content of trade incorrectly. Davis and Weinstein (2001) were right: the assumptions of identical 
technologies and factor price equalization just don't cut it in these data. Likewise, countries do not share a common technology matrix, even if one allows for Hicks-neutral technological difference or factor-specific efficiency units. Davis and Weinstein were prescient to show that the production specification for many of their different "models" performed much better than the trade specification, but they did not push this insight far enough. If the models work well for production but poorly for trade, then the problem in how we are measuring the factor content of imports.

Hakura (2001) was insightful to state that the concept of the factor content of trade becomes problematic in a model where production techniques differ across countries. But she was not able to pursue her insight far enough because no one had invented a way to measure factor content in a world where the supply side of France is different from that of Japan and factors are not mobile by assumption. Our major methodological contribution is to use the pseudo-inverse of each country's direct and indirect factor content of trade in a clever way. It is an amazing fact that the empirical implementation of our approach indicates that on average factor services shrink by 40 per cent when goods flow from one OECD country to another. And these are advanced industrial countries with fairly homogenous production structures!

Some of our analysis consisted of confirming what has been known before about simple trade models. Using the conventional Leontief measure of the factor content of trade, we confirmed Davis and Weinstein's (2001) findings. We think this makes our point about the proper measure of the factor content all the more salient.

Since we have assumed that traded goods cross only one international border, we have been conservative in implementing the Fisher-May measure of the factor content of 
trade. A fuller implementation of this method requires a different way of keeping international trade data in the aggregate. A perfect test of a theory of trade would keep track of value added at every stage of production, and the world economy is becoming increasingly fragmented. So these kinds of data are not easy to adduce. Still, we do not think the main conclusion of our work is nihilistic. We can state with some confidence now that the mystery of missing trade has to with an incorrect measure of the factor

content of imports. Also, our use of the Moore-Penrose inverse to get at the essence of the local factor content of trade is a nice applied theoretical and empirical contribution that future researchers can build upon.

\section{DATA APPENDIX}

The data and all the programs are available at http://economics.sbs.ohio-state.edu/efisher/fishermay .

The file

http://economics.sbs.ohio-state.edu/efisher/fishermay/DETAILED DATA APPENDIX.pdf gives a complete description of the raw data. We have included the references to the sources for these data in our bibliography for the sake of completeness.

\section{TECHNICAL APPENDIX}

This appendix, consisting of three examples, lends credence to the statements in the text explaining why the eigenvalues of the factor conversion matrices may have moduli less than unity. 
Recall that the factor conversion matrix is

$$
\mathbf{F}\left(c, c^{\prime}\right)=\left[\mathbf{W}^{c} \mathbf{B}^{c}\left(\mathbf{I}-\mathbf{A}^{c}\right)^{-1} \mathbf{P}^{-1}\right]\left[\mathbf{W}^{c^{\prime}} \mathbf{B}^{c^{\prime}}\left(\mathbf{I}-\mathbf{A}^{c^{\prime}}\right)^{-1} \mathbf{P}^{-1}\right]^{+}
$$

The first example shows the effect of different levels of productivity. Assume that $\mathbf{A}^{c}=\mathbf{A}^{c^{\prime}}$, so that there is no difference in the uses of intermediate inputs. Now let

$$
\mathbf{B}^{c}=\left[\begin{array}{lll}
\pi_{1} & & 0 \\
& \ddots & \\
0 & & \pi_{f}
\end{array}\right] \mathbf{B}^{c^{\prime}} .
$$

We will assume that $f=\ell$ and that $\mathbf{B}^{c^{\prime}}$ has full rank. Since all the matrices in (A1) are invertible, the factor conversion matrix is

$$
\mathbf{F}\left(c, c^{\prime}\right)=\mathbf{W}^{c}\left[\begin{array}{lll}
\pi_{1} & & 0 \\
& \ddots & \\
0 & & \pi_{f}
\end{array}\right]\left(\mathbf{W}^{c^{\prime}}\right)^{-1} .
$$

These are precisely the productivity differences that Trefler (1993b) studied. The eigenvalues of this diagonal matrix are simply the relative factor prices adjusted for factor-augmenting technical differences.

The second example shows the effect of different uses of intermediate inputs in each country. Now let $\mathbf{B}^{c}=\mathbf{B}^{c^{\prime}}$ so that the two countries have identical direct factor use. We will assume again that $f=\ell$ and that all matrices have full rank. Notice that

$$
\operatorname{det} \mathbf{F}\left(c, c^{\prime}\right)=\operatorname{det} \mathbf{W}^{c} \operatorname{det}\left(\mathbf{I}-\mathbf{A}^{c}\right)^{-1} \operatorname{det}\left(\mathbf{I}-\mathbf{A}^{c^{\prime}}\right) \operatorname{det}\left(\mathbf{W}^{c^{\prime}}\right)^{-1},
$$

where we have used the fact that $\operatorname{det}\left(\mathbf{B}^{c}\right) \operatorname{det}\left(\mathbf{B}^{c^{\prime}}\right)^{-1}=1$. Let $\lambda_{i}\left(c, c^{\prime}\right)$ be an eigenvalue of the factor conversion matrix. Since the determinant is the product of these values,

$$
\prod_{i=1}^{f} \lambda_{i}\left(c, c^{\prime}\right)=\prod_{i=1}^{f}\left(w_{i}^{c} / w_{i}^{c^{\prime}}\right) \prod_{j=1}^{\ell}\left(1-\alpha_{j}^{c^{\prime}}\right) /\left(1-\alpha_{j}^{c}\right)
$$


where $w_{i}^{c}$ is the return on factor $i$ in country $c, \alpha_{j}^{c}$ is the $j-$ th eigenvalue of $\mathbf{A}^{c}$. (We have used the fact that each eigenvalue of $\left(\mathbf{I}-\mathbf{A}^{c}\right)^{-1}$ corresponds to some1/(1- $\left.\alpha_{j}^{c}\right)$.) So these values are small if relative factor prices in the importing country are low or if the exporting country makes heavy use of intermediates.

These two examples explain why the importing country's factor conversion matrix might have eigenvalues with moduli less than unity, but they cannot explain the predominance of such values in a sample of country pairs. This fact is true because $\mathbf{F}\left(c, c^{\prime}\right)=\left[\mathbf{F}\left(c^{\prime}, c\right)\right]^{-1}$ if the number of factors is equal to the number of goods and all the constituent matrices in (A1) have full rank.

The last example shows why there will be a preponderance of eigenvalues with modulus less than unity when factor proportions between countries vary less across sectors within one country than they do across countries within the same sector. Now assume that $\ell>f>1$ and write

$$
\mathbf{F}\left(c, c^{\prime}\right)=\boldsymbol{\Theta}^{c}\left[\Theta^{c^{\prime}}\right]^{+}
$$

We will let

$$
\underset{f \times \ell}{\Theta^{c^{\prime}}}=\left[\begin{array}{ccc}
\theta_{1}^{c^{\prime}} & \cdots & \theta_{1}^{c^{\prime}} \\
\vdots & \ddots & \vdots \\
\theta_{f}^{c^{\prime}} & \cdots & \theta_{f}^{c^{\prime}}
\end{array}\right],
$$

so that each sector in the exporting country has the same factor proportions. In this case

$$
\underset{\ell \times f}{\left[\Theta^{c^{\prime}}\right]^{+}}=\left[\begin{array}{ccc}
\theta_{1}^{c^{\prime}} / \ell \sum_{i=1}^{f}\left(\theta_{i}^{c^{\prime}}\right)^{2} & \cdots & \theta_{f}^{c^{\prime}} / \ell \sum_{i=1}^{f}\left(\theta_{i}^{c^{\prime}}\right)^{2} \\
\vdots & \ddots & \vdots \\
\theta_{1}^{c^{\prime}} / \ell \sum_{i=1}^{f}\left(\theta_{i}^{c^{\prime}}\right)^{2} & \cdots & \theta_{f}^{c^{\prime}} / \ell \sum_{i=1}^{f}\left(\theta_{i}^{c^{\prime}}\right)^{2}
\end{array}\right] .
$$


This matrix has rank one. Since $\operatorname{rank}\left(\mathbf{F}\left(c, c^{\prime}\right)\right) \leq \min \left\{\operatorname{rank}\left(\Theta^{c}\right), \operatorname{rank}\left(\left[\Theta^{c^{\prime}}\right]^{+}\right)\right\}$, the factor conversion matrix is singular. Hence it has at least one zero eigenvalue. Since $\mathbf{F}\left(c^{\prime}, c\right)=\boldsymbol{\Theta}^{c^{\prime}}\left[\Theta^{c}\right]^{+}$and the rank of $\boldsymbol{\Theta}^{c^{\prime}}$ is also one, these zero eigenvalues come in pairs. This example is not generic, but it does illustrate how converting foreign factors into their domestic equivalents can drastically "shrink" factors in both directions.

\section{REFERENCES}

Albert, Arthur. Regression and the Moore-Penrose Pseudoinverse. Academic Press: New York, 1972

Bowen, Harry P., Edward E. Leamer, and Leo Sveikauskas. "Multicountry, Multifactor Tests of Factor Abundance Theory.” American Economic Review, December 1987, 77(5), pp. 791-809.

Checchi, Daniele and Cecilia García Peñalosa "Labour Market Insitutitions and the Personal Distribution of Income in the OECD.” November 2005, IZA Discussion Paper No. 1681.

Conway, Patrick J. “The Case of Missing Trade and other Mysteries: Comment.” American Economic Review, March 2002, 92(1), pp. 394-404.

Council of Economic Advisers. "Table B-7: Chain-type price indexes for gross domestic product, 1959-2003,” Economic Report of the President. Washington, DC: U.S. Government Printing Office, 2004.

Davis, Donald R. and David E. Weinstein. “An Account of Global Factor Trade.” American Economic Review, December 2001, 91(5), pp.1423-53. 
Debaere, Peter. “Relative Factor Abundance and Trade.” Journal of Political Economy, June 2003, 111(3), pp. 589-612.

Estevadeordal, Antoni and Alan M. Taylor. “A Century of Missing Trade?” American Economic Review, March 2002, 92(1), pp.383-93.

Eysenbach, Mary Locke. American Manufactured Exports, 1879-1914. New York: Arno Press, 1976.

Feenstra, Robert C. "Integration of Trade and Disintegration of Production in the Global Economy.” The Journal of Economic Perspectives, Autumn 1998, 12(4), pp. 31-50.

Feenstra, Robert C. and Gordon H. Hanson. "Aggregation Bias in the Factor Content of Trade: Evidence from U.S. Manufacturing.” American Economic Review Papers and Proceedings, May 2000, 90(2), pp.155-60.

Fisher, Eric O'N. and Sharon L. May. "Relativity in Trade Theory: Towards a Solution to the Mystery of Missing Trade.” Unpublished working paper, The Ohio State University, 2005. http://economics.sbs.ohio-state.edu/efisher/fisher_may0.pdf . "Homogeneous or Heterogeneous Factors? Measuring the Factor Content of Trade.” Unpublished working paper, The Ohio State University, 2006.

Gabaix, Xavier. "The Factor Content of Trade: A Rejection of the Heckscher-OhlinLeontief Hypothesis.” Working paper, Harvard University, May 1997.

Gollin, Douglas. “Getting Income Shares Right.” Journal of Political Economy, April 2002, 110(2), pp. 458-474.

Gorman, William. M. “On a Class of Preference Fields.” Metroeconomica, February 1961, 13(1), pp. 53-6. 
Hakura, Dalia S. "Why does HOV fail? The role of technological differences within the EC.” Journal of International Economics, August 2001, 54(2), pp. 361-382.

Harkness, Jon. “Factor Abundance and Comparative Advantage.” American Economic Review, December 1978, 68(5), pp. 784-800.

Helpman, Elhanan. “The Structure or Foreign Trade.” Journal of Economic Perspectives, Spring 1999, 13(2), pp. 121-44.

Heston, Alan, Robert Summers, and Bettina Aten. "Penn World Table Version 6.1." Center for International Comparisons, University of Pennsylvania (CICUP), October 2002.

Kemp, Murray C. and Henry Y. Wan, Jr. “An Elementary Proposition Concerning the Formation of Customs Unions.” Journal of International Economics, February 1976, 6(1), pp. 95-97.

Krueger, Alan B. “Measuring Labor’s Share.” American Economic Review Papers and Proceedings, May 1999, 89(2), pp. 45-51.

Leamer, Edward E. Sources of International Comparative Advantage: Theory and Evidence. MIT Press: Cambridge, 1984.

Leontief, Wassily. Input-Output Economics ( $2^{\text {nd }}$ ed.). New York: Oxford University Press, 1986.

Organisation for Economic Co-operation and Development. "Bilateral Trade Database 2000.” April 2000. http://www.oecd.org/document/4/0,2340,en_2825_293564_1895684_1_1_1_1,00. $\underline{\mathrm{html}}$ 
. “Input Output Tables.” November 2000.

http://www.oecd.org/document/6/0,2340,en_2825_495684_2672966_1_1_1_1,00. $\underline{\text { html }}$

. “Annual National Accounts Table 3: GDP by Income.” July 2004.

http://cs4hq.oecd.org/oecd/eng/TableViewer/Wdsview/dispviewp.asp?ReportId=1 849\&bReportOnly=True

Reimer, Jeffrey J. "Global Production Sharing and Trade in the Services of Factors.” Journal of International Economics, March 2006, 68(2), pp. 384-408.

Sanyal, Kalyan K. and Ronald W. Jones. "The Theory of Trade in Middle Products.” American Economic Review, March 1982, 72(1), pp. 16-31.

Schott, Peter K. “One Size Fits All? Heckscher-Ohlin Specification in Global Production.” American Economic Review, June 2003, 93(3), pp.686-708.

Schreyer, Paul and Wim Suyker. "Creation of the Euro Area: Implications for Economic Statistics.” OECD Statistics Brief No. 2, February 2002. http://www.oecd.org/dataoecd/19/3/1844573.pdf

Tempest, Rone. "Barbie and the World Economy.” Los Angeles Times, September 22, 1996, pp. A1 and A12.

Trefler, Daniel. “Trade Liberalization and the Theory of Endogenous Protection: An Econometric Study of U.S. Import Policy.” Journal of Political Economy, February 1993a, 101(1), pp. 138-60.

. “International Factor Price Differences: Leontief was Right!” Journal of Political Economy, December 1993b, 101(6), pp. 961-87. 
. “The Case of Missing Trade and Other Mysteries.” American Economic Review, December 1995, 85(5), pp. 1029-46.

Trefler, Daniel and Susan C. Zhu. “The Structure of Factor Content Predictions.” Working paper, Michigan State University, 2006. http://www.msu.edu/ zhuc/Structure_of_Factor_Content_Prediction.pdf

Vanek, Jaroslav. The Natural Resource Content of United States Foreign Trade, 18701955. Cambridge, Massachusetts: The MIT Press, 1963. . “The Factor Proportions Theory: The N-Factor Case.” Kyklos, October 1968, 21(4), pp. 749-56. 
Table 1: How Similar are the Supply Sides of these Nine Countries?

Correlations of Labor's Shares

AUS CAN DMK FRA GER ITA JAP UK USA

\begin{tabular}{|c|c|c|c|c|c|c|c|c|}
\hline AUS & 1.00 & 0.25 & 0.67 & 0.70 & 0.27 & 0.39 & 0.43 & 0.75 \\
\hline CAN & & 1.00 & 0.16 & 0.47 & 0.10 & 0.75 & -0.15 & 0.69 \\
\hline DMK & & & 1.00 & 0.49 & 0.14 & 0.33 & 0.37 & 0.57 \\
\hline FRA & & & & 1.00 & 0.37 & 0.52 & 0.39 & 0.79 \\
\hline GER & & & & & 1.00 & 0.05 & 0.55 & 0.19 \\
\hline ITA & & & & & & 1.00 & -0.14 & 0.66 \\
\hline JAP & & & & & & & 1.00 & 0.18 \\
\hline UK & & & & & & & & 1.00 \\
\hline USA & & & & & & & & \\
\hline
\end{tabular}

Correlations of Private Capital's Shares

AUS CAN DMK FRA GER ITA JAP UK USA

\begin{tabular}{|c|c|c|c|c|c|c|c|c|}
\hline AUS & 1.00 & -0.32 & 0.67 & 0.17 & 0.50 & -0.04 & 0.59 & 0.21 \\
\hline CAN & & 1.00 & 0.17 & 0.19 & -0.16 & 0.07 & -0.27 & 0.54 \\
\hline DMK & & & 1.00 & 0.49 & 0.39 & 0.28 & 0.48 & 0.69 \\
\hline FRA & & & & 1.00 & 0.51 & 0.44 & 0.63 & 0.60 \\
\hline GER & & & & & 1.00 & 0.32 & 0.59 & 0.16 \\
\hline ITA & & & & & & 1.00 & 0.31 & 0.24 \\
\hline JAP & & & & & & & 1.00 & 0.26 \\
\hline
\end{tabular}


Correlations of Social Capital's Shares

AUS CAN DMK FRA GER ITA JAP UK USA

\begin{tabular}{|c|c|c|c|c|c|c|c|c|}
\hline AUS & 1.00 & 0.12 & -0.21 & 0.62 & 0.31 & 0.51 & 0.60 & -0.17 \\
\hline CAN & & 1.00 & -0.15 & 0.12 & -0.06 & 0.20 & -0.07 & 0.18 \\
\hline DMK & & & 1.00 & 0.03 & 0.75 & -0.01 & 0.11 & -0.12 \\
\hline FRA & & & & 1.00 & 0.28 & 0.45 & 0.40 & 0.03 \\
\hline GER & & & & & 1.00 & 0.37 & 0.56 & -0.26 \\
\hline ITA & & & & & & 1.00 & 0.66 & -0.10 \\
\hline JAP & & & & & & & 1.00 & -0.08 \\
\hline UK & & & & & & & & 1.00 \\
\hline USA & & & & & & & & \\
\hline
\end{tabular}


Table 2: Model Fit Using the Fisher-May Measure

\begin{tabular}{lrr} 
& Model & \multicolumn{2}{c}{ Number of } \\
& Summary & Correct Signs \\
& Statistic & (of 27) \\
Maximum & 0.275 & 19 \\
Minimum & 0.118 & 17 \\
Median & 0.219 & 16.9 \\
Mean & 0.218 & $(0.55)$ \\
(standard deviation) & $(0.015)$ &
\end{tabular}


Figure 1: Predicted Aggregate Factor Shares

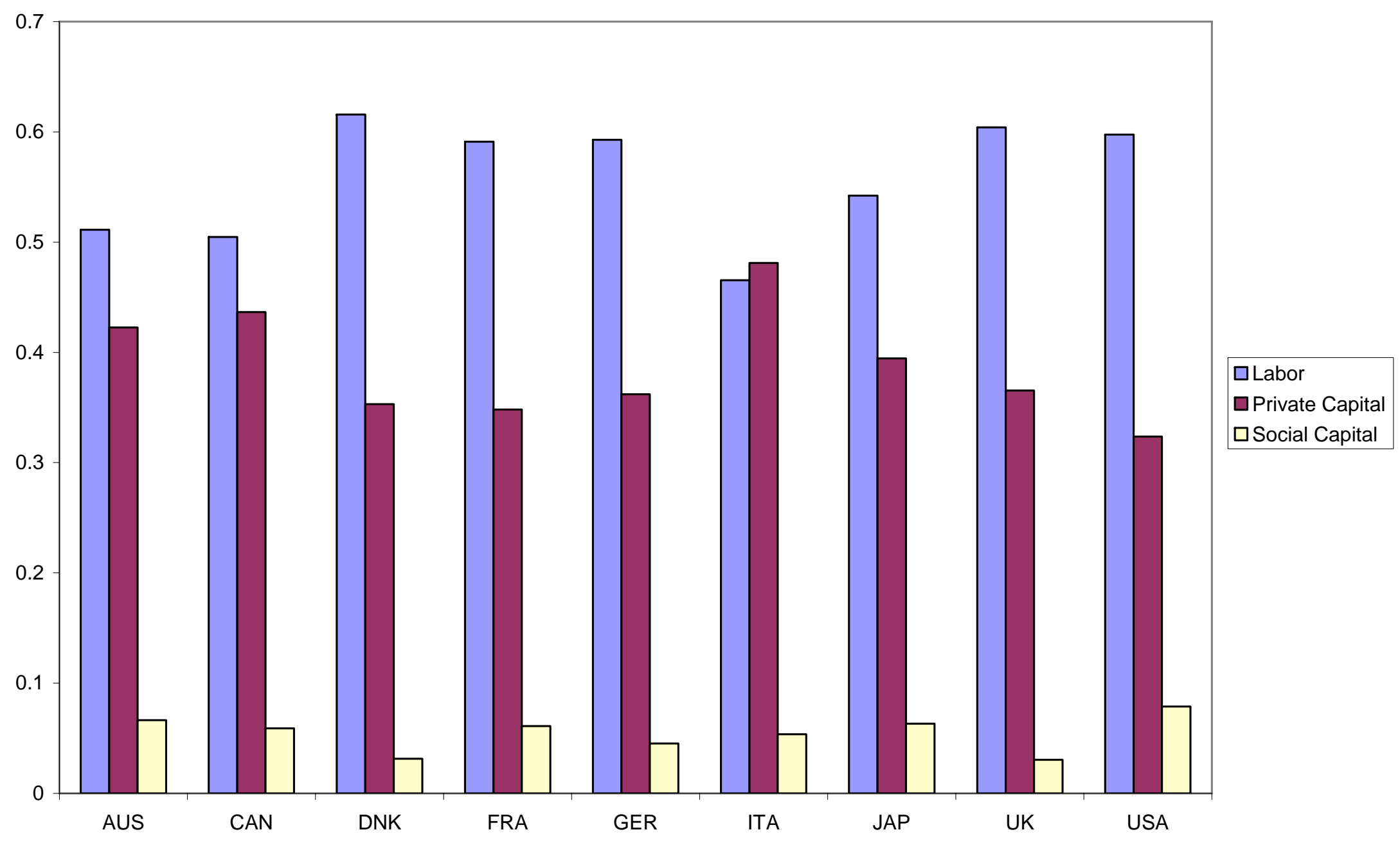


Figure 2: Production Test

(millions of 1985 \$US)

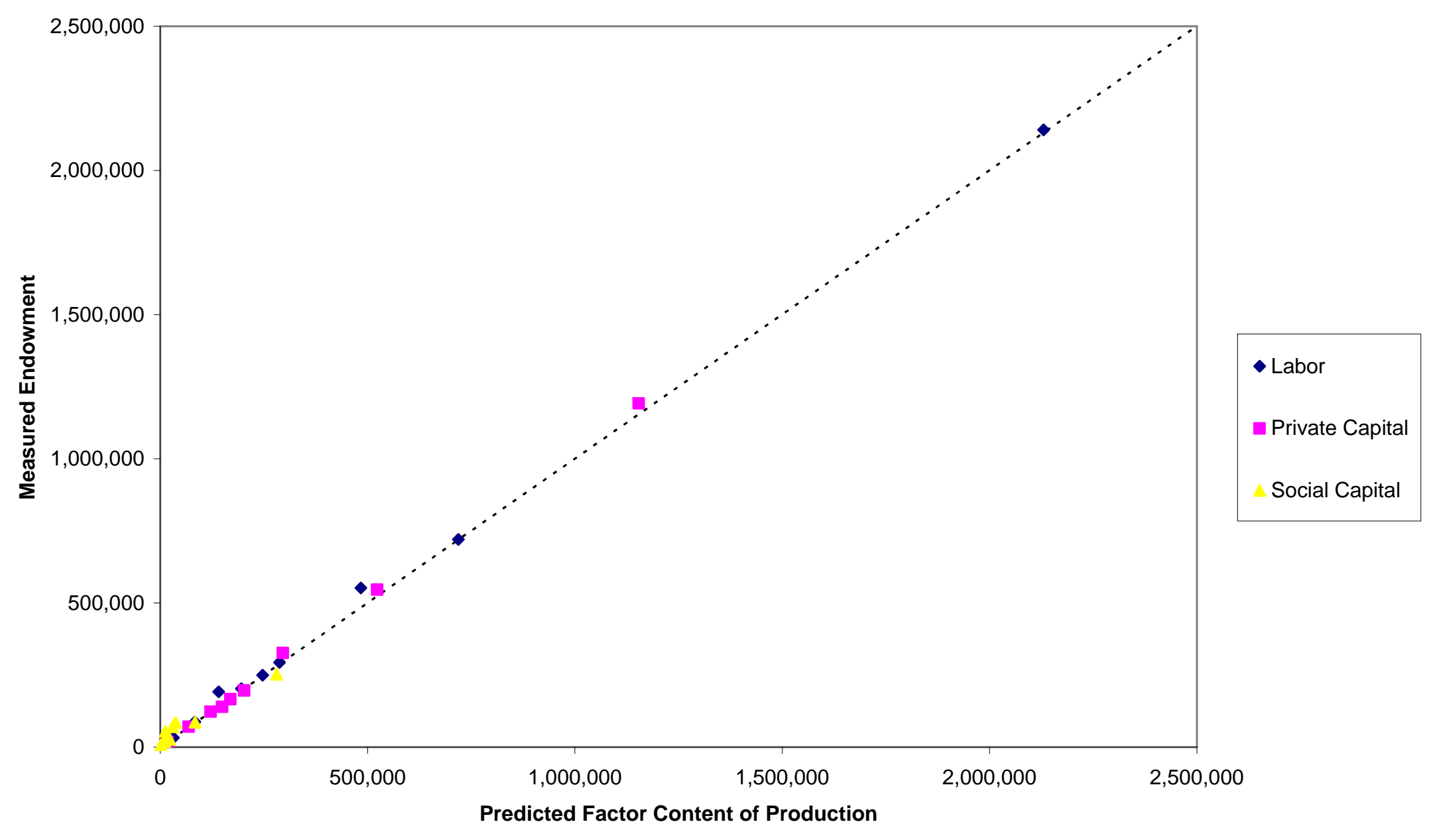


Figure 3: Basic Trade Test

(millions of 1985 \$US)

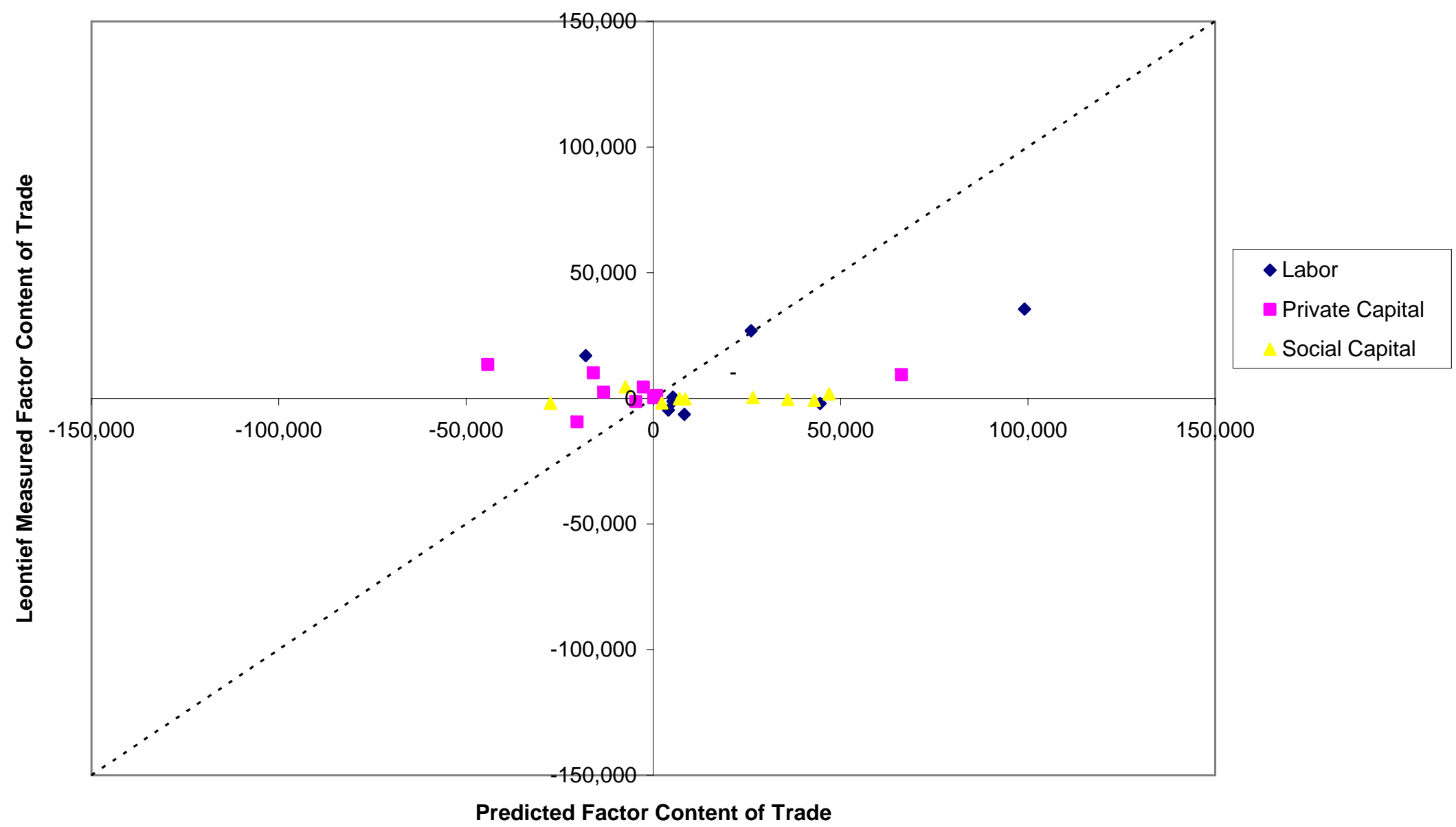


Figure 4: Trade Test with a Narrow Definition of Not Traded Goods

(millions of 1985 \$US)

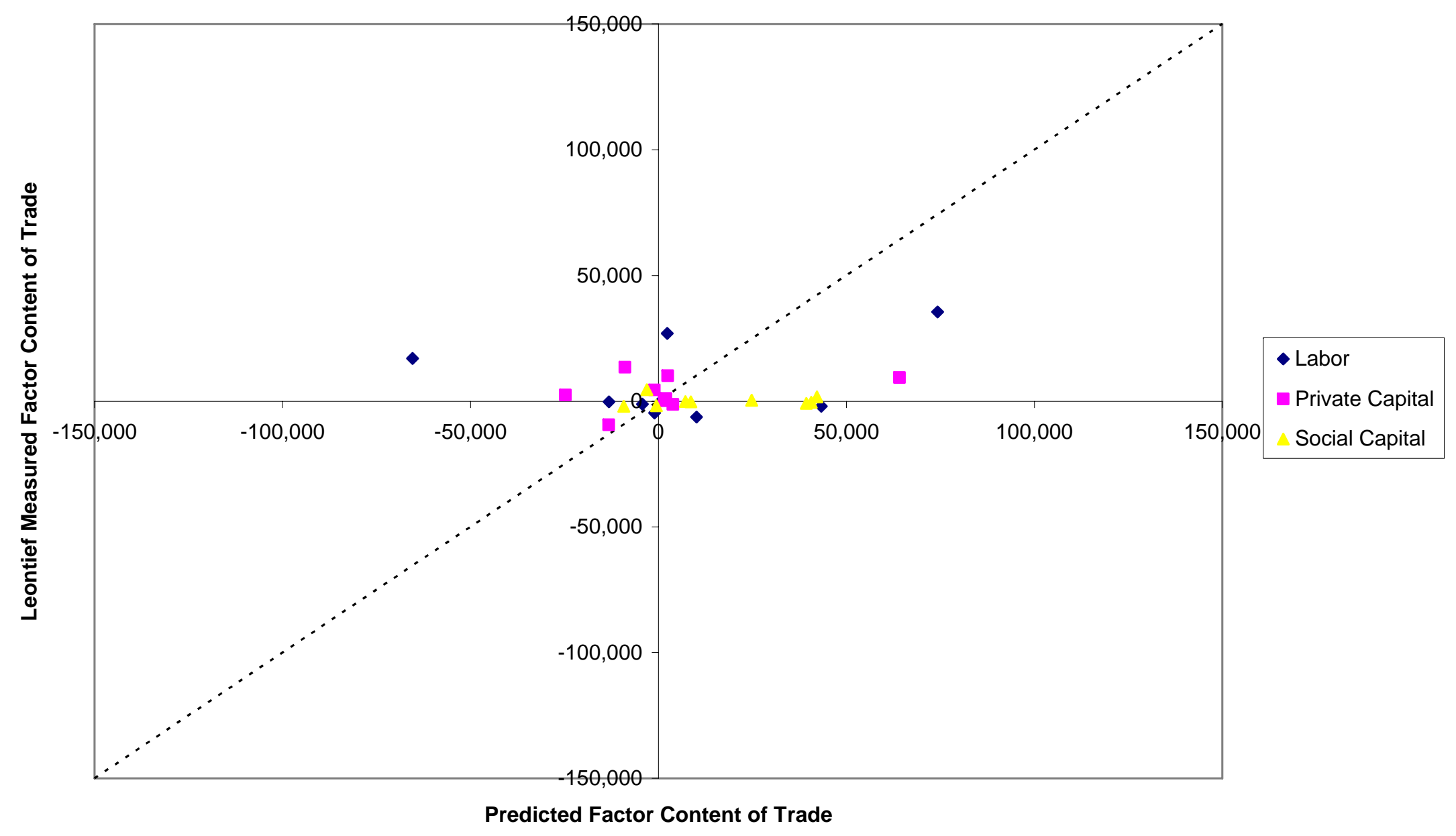


Figure 5: Histogram of the Eigenvalues of the Factor Conversion Matrices

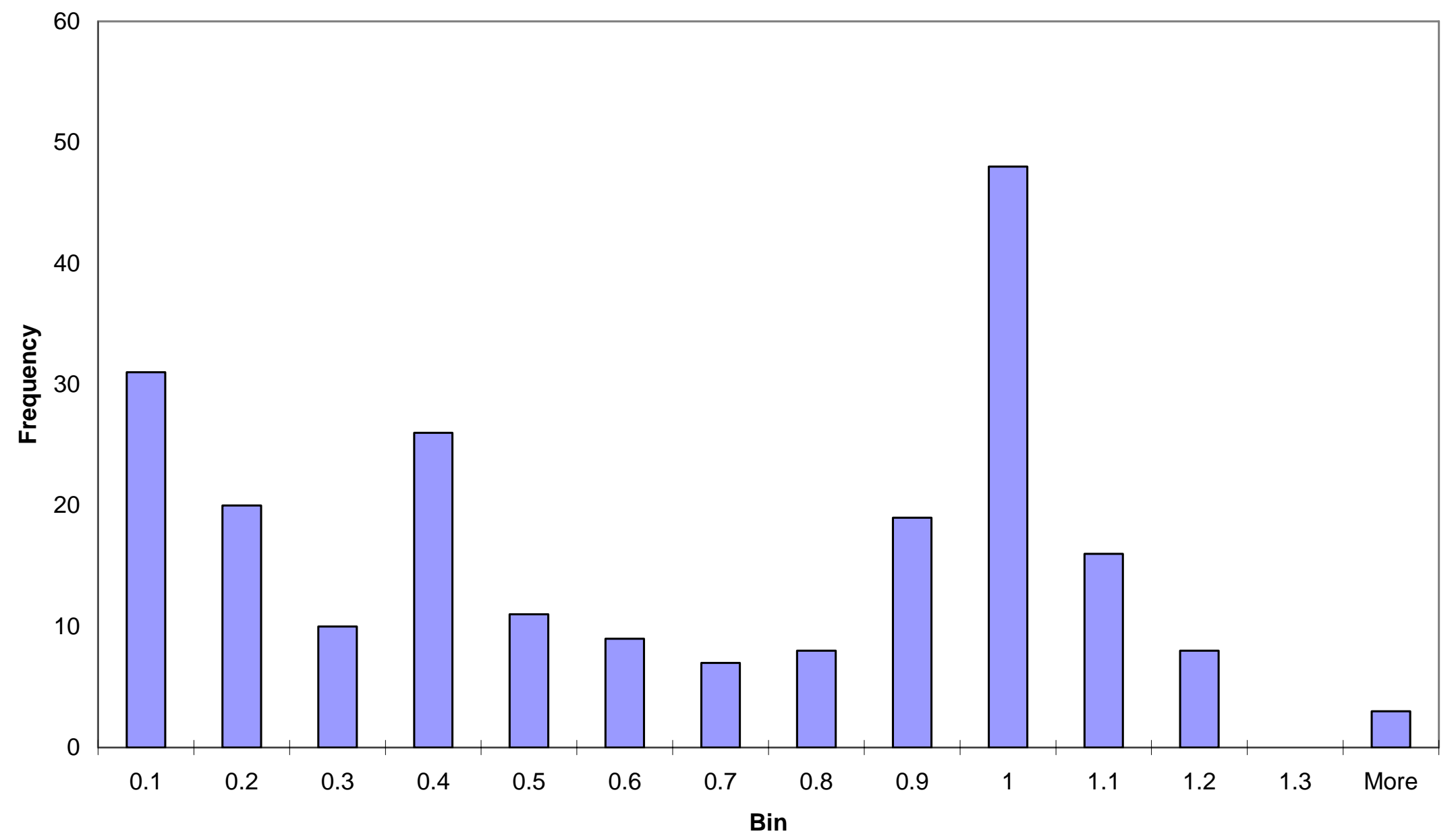


Figure 6 : Best Fit Fisher-May Measure of the Factor Content of Trade (millions of 1985 \$US)

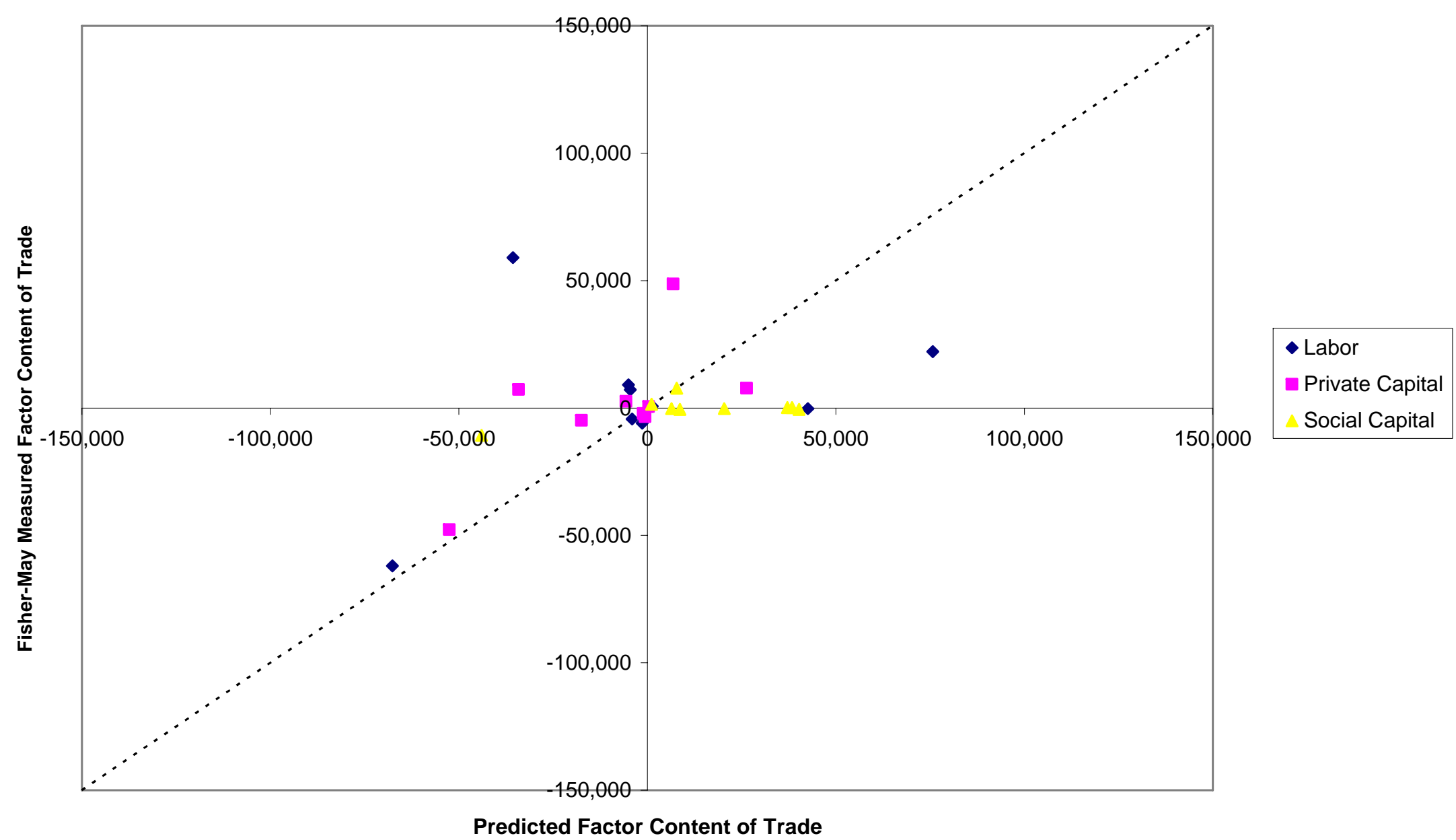




\section{ENDNOTES}

* Fisher: Orfalea College of Business, California Polytechnic State University, 1 Grand Avenue, San Luis Obispo, CA 93407 (e-mail: eric.on.fisher@gmail.com); May: Division of Social Sciences of Economics, Maryville College, 502 E. Lamar Alexander Parkway, Maryville, TN 37804 (e-mail: slmay@msn.com). The data and Gauss programs that were used in this paper are available at http://economics.sbs.ohiostate.edu/efisher/fishermay The authors would like to thank two anonymous referees, Dave Richardson, Dave Hummels, Pat Conway, Eric van Wincoop, Jim Anderson, Jim Harrigan, Jon Haveman, Kathryn Marshall, and seminar participants at the Federal Reserve Bank of Cleveland, Virginia Tech, the University of Virginia, the University of North Carolina, Miami University of Ohio, the Midwest International Economics Meetings at Washington University of St. Louis, Purdue University, The Ohio State University, the University of Alicante, the 2005 Conference of the Pennsylvania Economics Association, Empirical Investigations in International Trade at Ljubljana in 2005, and the University of California at Davis for comments on earlier drafts.

${ }^{1}$ Using Trefler's own data, Patrick J. Conway (2002) suggests that sluggish movement of factors across industries may account for the low volume of trade observed in the data. Antoni Estevadeordal and Alan M. Taylor (2002) show that there was too little trade even a century ago. On the other hand, Donald R. Davis and David E. Weinstein (2001) argue that a model without factor price equalization but with non-traded goods and home bias in consumption is consistent with the data. Also, Peter Debaere (2003) shows that the 
model predicts the direction of trade well for country pairs whose factor endowments are quite different.

${ }^{2}$ Harry P. Bowen, Edward E. Leamer and Leo Sveikauskas (1987) is seminal. Jeffrey J. Reimer (2006) develops a method for measuring the factor content of traded intermediate inputs; he concludes that a careful treatment of intermediate goods may make it more difficult to account for missing trade. Daniel Trefler and Susan C. Zhu (2005) recognize that the definition of the factor content of trade is problematic when traded intermediate inputs are made with different local techniques. Fisher and May (2006) extends Reimer's work to include country-specific factor differences.

${ }^{3}$ Robert C. Feenstra and Gordon H. Hanson (2000) point out that sectoral aggregation may well cause bias in the measured factor content of trade. We think this is a very important insight. Indeed, Trefler's (1993a) calculations of the direct and indirect factor requirements matrix for disaggregated manufacturing data seem much more reasonable to us than the ones based upon output for the entire economy of the United States.

${ }^{4}$ Vanek (1963) was already aware of this issue in his doctoral thesis, and Mary Locke Eysenbach (1976) struggles with how best to measure capital in her study. Jon Harkness (1978) also confronted this problem and made some ad hoc assumptions about the rates of return to crop land and pasture land. These researchers were grappling with a problem that any empirical scholar using applied general equilibrium theory must confront. The techniques used by Vanek, Eysenbach, and Harkness, who were writing more than a generation ago, are perhaps more transparent that what is being done today. 
${ }^{5}$ We interpret social capital as the physical and institutional public infrastructure within which economic activity occurs. The rents on social capital are a country's sectorspecific pattern of indirect business taxes or subsidies. It is more usual to consider the private economy net of government services, but that would add some noise into the data we analyze. Also, it is quite obvious from these raw input output matrices that some sectors (like mining in Canada) are a net burden on the economy, whereas others (like food, beverages \& tobacco in Japan) are robust enough to pay substantial rents for the use of social capital. So we hope to achieve some insight by thinking of indirect taxes as payments on social capital. Here is an even more trenchant reason for including social capital as a factor of production. Consider two otherwise identical countries whose patterns of indirect taxation differ across industries. This pair would have different factor prices, and the measured factor content of any common vector of goods would differ. Thus industry-specific patterns of taxation are just as much a part of the technology matrix of a country as are different production techniques. In our data, there is indisputable evidence that these patterns of the use of social capital are different among these nine countries.

${ }^{6}$ In practice, there may be some direct demand for factors of production by households, but in the data we analyze these are almost completely negligible. Imposing the assumption of constant returns to scale, it is customary to normalize $A$ and $B$ by dividing by industry output. The first $\ell$ row and column totals of the larger matrix are equal, so it is just as easy to divide the sub-matrices by its column totals. 
${ }^{7}$ Let $\mathbf{X}$ be an $n \times m$ matrix. Then its Moore-Penrose inverse $\mathbf{Y}$ is (the unique) $m \times n$ matrix such that $\mathbf{X Y X}=\mathbf{X}, \mathbf{Y X Y}=\mathbf{Y}, \mathbf{X Y}$ is symmetric, and $\mathbf{Y X}$ is symmetric. ${ }^{8}$ Albert (1972, p. 56) shows that if $\underset{n \times r}{\mathbf{A}}$ and $\underset{r \times m}{\mathbf{B}}$ both have rank $r$, then $(\mathbf{A B})^{+}=\mathbf{B}^{+} \mathbf{A}^{+}$. Hence, if $\left(\Theta^{c}\right)^{+} \mathbf{W}^{c} \mathbf{v}^{c}=\left[\mathbf{B}^{c}\left(\mathbf{I}-\mathbf{A}^{c}\right)^{-1} \mathbf{P}^{-1}\right]^{+}\left(\mathbf{W}^{c}\right)^{-1} \mathbf{W}^{c} \mathbf{v}^{c} \mathbf{B}^{c}$ has full column rank, then $\left(\Theta^{c}\right)^{+} \mathbf{W}^{c} \mathbf{v}^{c}=\left[\mathbf{B}^{c}\left(\mathbf{I}-\mathbf{A}^{c}\right)^{-1} \mathbf{P}^{-1}\right]^{+}\left(\mathbf{W}^{c}\right)^{-1} \mathbf{W}^{c} \mathbf{v}^{c}$ because $\mathbf{W}^{c}$ is diagonal with all positive elements and hence invertible.

${ }^{9}$ In our data, repeated applications of (3) would account for a lot of missing trade. Goods are indeed transshipped several times in the assembly process, since the bulk of international trade occurs in middle goods whose theoretical properties were first explored by Kalyan K. Sanyal and Ronald W. Jones (1982). As we have emphasized, our measure of factor content gives rise to a conservative test of the theory because it allows for much missing trade in intermediate goods.

${ }^{10}$ It is more elegant to write $\overline{\mathbf{v}}^{c}=\sum_{c^{\prime} \in \mathcal{C}} \mathbf{F}\left(c, c^{\prime}\right) \mathbf{W}^{c^{\prime}} \mathbf{v}^{c^{\prime}}+\mathbf{F}(c, 0) \mathbf{W}^{0} \mathbf{v}^{0}$ where the last term $\mathbf{F}(c, 0)=\Theta^{c}\left(\Theta^{0}\right)^{+}$involves the analogous data from the rest of the world. Unfortunately, neither the factor requirements matrix for the rest of the world $\Theta^{0}$ nor its endowment vector $\mathbf{W}^{0} \mathbf{v}^{0}$ is observable in our data, whereas the net trade vector $\mathbf{P} \mathbf{z}^{0}$ is.

${ }^{11}$ These data were sampled at the height of the Thatcher revolution.

12 Douglas Gollin (2002) emphasizes correctly that simple measures of labor share may be problematic when the labor income of the self employed is treated as capital income. He reports naïve labor shares for Australia, Denmark, France, Germany, Japan, the United Kingdom, and United States that are similar to ours. Daniele Checchi and Cecilia 
Garcia Peñalosa (2005) study a panel of data from the OECD, and compute labor shares that are quite close to ours. Alan B. Krueger (1999) is points out that almost all of what is called labor income is really the return to human capital; his insight suggests that international economists should use careful measures of human capital in future empirical research in this area.

${ }^{13}$ In essence, we are using the seminal insight of Murray C. Kemp and Henry Y. Wan, Jr. (1976) in analyzing a "world economy" consisting of these nine countries and an exogenously given net trade vector that is actually in the data. The nine OECD economies in our data actually account for about 54 per cent of world output in 1985.

${ }^{14}$ In the data for the Unites States in the last few years the balance on invisibles has been more positive than the balance on merchandise trade. Many of these invisibles are “services” that might be classified naively as not traded.

${ }^{15}$ We had to use aggregate trade flows because we wanted the same set of goods to be not traded in all the nine countries. In the end, our not traded sectors are: construction: community, social \& personal services; and producers of government services. 16 We estimated a system of identical quasi-homothetic preferences in William M. Gorman (1961) polar form, the most general specification of demand that allows for aggregation and is consistent with our data. This generalization did not account for much missing trade at all. It is possible that unmeasured trade costs account for missing trade, and our use of the pseudo inverse allows us to back out an exact specification of demand that would account for all conventionally measured factor content of trade. We 
concluded that the implicit trade costs were just too high to be plausible. This topic is a fruitful area for future research.

${ }^{17}$ What happens if we measure each country's exports using the local input-output matrix but do not convert factors from one country into those in another? In that case, 13 of the 27 signs are right and the median of ratios of the measured factor content to its predicted value is -0.02 . 


\title{
CESifo Working Paper Series
}

\author{
(for full list see www.cesifo-group.de)
}

1756 Richard Schmidtke, Private Provision of a Complementary Public Good, July 2006

1757 J. Atsu Amegashie, Intentions and Social Interactions, July 2006

1758 Alessandro Balestrino, Tax Avoidance, Endogenous Social Norms, and the Comparison Income Effect, July 2006

1759 Øystein Thøgersen, Intergenerational Risk Sharing by Means of Pay-as-you-go Programs - an Investigation of Alternative Mechanisms, July 2006

1760 Pascalis Raimondos-Møller and Alan D. Woodland, Steepest Ascent Tariff Reforms, July 2006

1761 Ronald MacDonald and Cezary Wojcik, Catching-up, Inflation Differentials and Credit Booms in a Heterogeneous Monetary Union: Some Implications for EMU and new EU Member States, July 2006

1762 Robert Dur, Status-Seeking in Criminal Subcultures and the Double Dividend of ZeroTolerance, July 2006

1763 Christa Hainz, Business Groups in Emerging Markets - Financial Control and Sequential Investment, July 2006

1764 Didier Laussel and Raymond Riezman, Fixed Transport Costs and International Trade, July 2006

1765 Rafael Lalive, How do Extended Benefits Affect Unemployment Duration? A Regression Discontinuity Approach, July 2006

1766 Eric Hillebrand, Gunther Schnabl and Yasemin Ulu, Japanese Foreign Exchange Intervention and the Yen/Dollar Exchange Rate: A Simultaneous Equations Approach Using Realized Volatility, July 2006

1767 Carsten Hefeker, EMU Enlargement, Policy Uncertainty and Economic Reforms, July 2006

1768 Giovanni Facchini and Anna Maria Mayda, Individual Attitudes towards Immigrants: Welfare-State Determinants across Countries, July 2006

1769 Maarten Bosker and Harry Garretsen, Geography Rules Too! Economic Development and the Geography of Institutions, July 2006

1770 M. Hashem Pesaran and Allan Timmermann, Testing Dependence among Serially Correlated Multi-category Variables, July 2006 
1771 Juergen von Hagen and Haiping Zhang, Financial Liberalization in a Small Open Economy, August 2006

1772 Alessandro Cigno, Is there a Social Security Tax Wedge?, August 2006

1773 Peter Egger, Simon Loretz, Michael Pfaffermayr and Hannes Winner, Corporate Taxation and Multinational Activity, August 2006

1774 Jeremy S.S. Edwards, Wolfgang Eggert and Alfons J. Weichenrieder, The Measurement of Firm Ownership and its Effect on Managerial Pay, August 2006

1775 Scott Alan Carson and Thomas N. Maloney, Living Standards in Black and White: Evidence from the Heights of Ohio Prison Inmates, 1829 - 1913, August 2006

1776 Richard Schmidtke, Two-Sided Markets with Pecuniary and Participation Externalities, August 2006

1777 Ben J. Heijdra and Jenny E. Ligthart, The Transitional Dynamics of Fiscal Policy in Small Open Economies, August 2006

1778 Jay Pil Choi, How Reasonable is the 'Reasonable' Royalty Rate? Damage Rules and Probabilistic Intellectual Property Rights, August 2006

1779 Ludger Woessmann, Efficiency and Equity of European Education and Training Policies, August 2006

1780 Gregory Ponthiere, Growth, Longevity and Public Policy, August 2006

1781 Laszlo Goerke, Corporate and Personal Income Tax Declarations, August 2006

1782 Florian Englmaier, Pablo Guillén, Loreto Llorente, Sander Onderstal and Rupert Sausgruber, The Chopstick Auction: A Study of the Exposure Problem in Multi-Unit Auctions, August 2006

1783 Adam S. Posen and Daniel Popov Gould, Has EMU had any Impact on the Degree of Wage Restraint?, August 2006

1784 Paolo M. Panteghini, A Simple Explanation for the Unfavorable Tax Treatment of Investment Costs, August 2006

1785 Alan J. Auerbach, Why have Corporate Tax Revenues Declined? Another Look, August 2006

1786 Hideshi Itoh and Hodaka Morita, Formal Contracts, Relational Contracts, and the Holdup Problem, August 2006

1787 Rafael Lalive and Alejandra Cattaneo, Social Interactions and Schooling Decisions, August 2006 
1788 George Kapetanios, M. Hashem Pesaran and Takashi Yamagata, Panels with Nonstationary Multifactor Error Structures, August 2006

1789 Torben M. Andersen, Increasing Longevity and Social Security Reforms, August 2006

1790 John Whalley, Recent Regional Agreements: Why so many, why so much Variance in Form, why Coming so fast, and where are they Headed?, August 2006

1791 Sebastian G. Kessing and Kai A. Konrad, Time Consistency and Bureaucratic Budget Competition, August 2006

1792 Bertil Holmlund, Qian Liu and Oskar Nordström Skans, Mind the Gap? Estimating the Effects of Postponing Higher Education, August 2006

1793 Peter Birch Sørensen, Can Capital Income Taxes Survive? And Should They?, August 2006

1794 Michael Kosfeld, Akira Okada and Arno Riedl, Institution Formation in Public Goods Games, September 2006

1795 Marcel Gérard, Reforming the Taxation of Multijurisdictional Enterprises in Europe, a Tentative Appraisal, September 2006

1796 Louis Eeckhoudt, Béatrice Rey and Harris Schlesinger, A Good Sign for Multivariate Risk Taking, September 2006

1797 Dominique M. Gross and Nicolas Schmitt, Why do Low- and High-Skill Workers Migrate? Flow Evidence from France, September 2006

1798 Dan Bernhardt, Stefan Krasa and Mattias Polborn, Political Polarization and the Electoral Effects of Media Bias, September 2006

1799 Pierre Pestieau and Motohiro Sato, Estate Taxation with Both Accidental and Planned Bequests, September 2006

1800 Øystein Foros and Hans Jarle Kind, Do Slotting Allowances Harm Retail Competition?, September 2006

1801 Tobias Lindhe and Jan Södersten, The Equity Trap, the Cost of Capital and the Firm's Growth Path, September 2006

1802 Wolfgang Buchholz, Richard Cornes and Wolfgang Peters, Existence, Uniqueness and Some Comparative Statics for Ratio- and Lindahl Equilibria: New Wine in Old Bottles, September 2006

1803 Jan Schnellenbach, Lars P. Feld and Christoph Schaltegger, The Impact of Referendums on the Centralisation of Public Goods Provision: A Political Economy Approach, September 2006 
1804 David-Jan Jansen and Jakob de Haan, Does ECB Communication Help in Predicting its Interest Rate Decisions?, September 2006

1805 Jerome L. Stein, United States Current Account Deficits: A Stochastic Optimal Control Analysis, September 2006

1806 Friedrich Schneider, Shadow Economies and Corruption all over the World: What do we really Know?, September 2006

1807 Joerg Lingens and Klaus Waelde, Pareto-Improving Unemployment Policies, September 2006

1808 Axel Dreher, Jan-Egbert Sturm and James Raymond Vreeland, Does Membership on the UN Security Council Influence IMF Decisions? Evidence from Panel Data, September 2006

1809 Prabir De, Regional Trade in Northeast Asia: Why do Trade Costs Matter?, September 2006

1810 Antonis Adam and Thomas Moutos, A Politico-Economic Analysis of Minimum Wages and Wage Subsidies, September 2006

1811 Guglielmo Maria Caporale and Christoph Hanck, Cointegration Tests of PPP: Do they also Exhibit Erratic Behaviour?, September 2006

1812 Robert S. Chirinko and Hisham Foad, Noise vs. News in Equity Returns, September 2006

1813 Oliver Huelsewig, Eric Mayer and Timo Wollmershaeuser, Bank Behavior and the Cost Channel of Monetary Transmission, September 2006

1814 Michael S. Michael, Are Migration Policies that Induce Skilled (Unskilled) Migration Beneficial (Harmful) for the Host Country?, September 2006

1815 Eytan Sheshinski, Optimum Commodity Taxation in Pooling Equilibria, October 2006

1816 Gottfried Haber and Reinhard Neck, Sustainability of Austrian Public Debt: A Political Economy Perspective, October 2006

1817 Thiess Buettner, Michael Overesch, Ulrich Schreiber and Georg Wamser, The Impact of Thin-Capitalization Rules on Multinationals' Financing and Investment Decisions, October 2006

1818 Eric O’N. Fisher and Sharon L. May, Relativity in Trade Theory: Towards a Solution to the Mystery of Missing Trade, October 2006 